\title{
Barriers and Enablers of Achievement in Brunei General Certificate of Education Advanced Level Psychology: Views of Trainee Psychology Teachers and Sixth Form Psychology Secondary School Students
}

\author{
Lawrence Mundia* \\ Psychological Studies and Human Development Academic Group, \\ Sultan Hassanal Bolkiah Institute of Education, \\ University of Brunei Darussalam, \\ Brunei Darussalam
}

\begin{abstract}
Psychology is a new and popular school subject in Brunei that challenges students. Being a difficult subject, this study investigated the perceived barriers to and enablers of achievement in Brunei General Certificate of Education Advanced Level psychology. The research used a descriptive survey design that collected quantitative data from nine university psychology trainee teachers (seven females and two males) as well as qualitative data from 118 Year 13 psychology secondary school students (84 females and 34 males). Major findings from quantitative data were determined by significant mean scores $(\geq 4.00, p<.05)$ and $95 \%$ confidence intervals. However, important findings from qualitative data were identified by the use of categories, themes and excerpts. Altogether, barriers to achievement included lack of clarity and lack of specificity in test items; difficulties in understanding examination questions; low skills in statistics; inadequate research skills; difficult research design items; and absence of educational interventions. Overall, enablers of achievement were: early identification of vulnerable students; effective teaching; appropriate study strategies; possessing higher-order skills; thinking critically; having positive self-concept and self-esteem; availability of suitable learning materials; motivation; help-seeking; receiving help; possessing good facility in English; and practicing answering questions. Participants' suggested and desired educational interventions to improve achievement included the provision of guidelines on answering examination questions effectively; more discussion of revision questions during practice sessions; and the teaching of critical thinking and time management skills. These interventions appear to be feasible and achievable if both psychology teachers (preservice and in-service) and psychology secondary school students are sensitized and upgraded on the identified barriers and enablers. There
\end{abstract}

*Corresponding author: Lawrence Mundia, Email: lawrence.mundia@ubd.edu.bn 
was ample evidence suggesting that psychology secondary school students need to be counseled and guided on the use of effective learning and study strategies. Further large-scale research with interview probes was recommended to obtain more insights and solutions to the problem.

Keywords: Pychology; pre-university; achievement; barriers; enablers; general certificate of education.

\section{Introduction and background}

Psychology is a relatively new school subject in the Brunei educational system. The subject is not taught at Year 11 (General Certificate of Education Ordinary, GCE O-Level) but only taught to Year 12 (General Certificate of Education Advanced Subsidiary, GCE AS-Level) and Year 13 (General Certificate of Education Advanced, GCE A-Level) students. Students' interest in and demand for the subject are quite high as the subject leads to many science career paths such as becoming a practitioner psychologist, psychotherapist, counselor, psychiatrist, mental health specialist, forensic scientist, criminologist, and many other related professions. To meet the instructional needs of psychology students in Sixth Form Colleges, the Sultan Hassanal Bolkiah Institute of Education (SHBIE) at the Universiti Brunei Darussalam (UBD) embarked on the training of psychology subject teachers locally from 2008 until the demand was met. Other Bruneian teachers of psychology received their training from overseas universities. However, students' performance in the subject is not high. Psychology is a cognitive science subject closely related to biology, psychiatry and mental health. The psychology subject in Brunei is taught mainly using journal articles on quantitative experimental research designs and statistics. Students with insufficient background in subjects or disciplines such as biology, mathematics and statistics often struggle in psychology despite having high interest. This concern provided the rationale and justification to conduct the present study. The current study sought to identify the barriers and enablers of achievement in the psychology subject in Brunei GCE A-Level students. Many factors are related to academic achievement in many school subjects including psychology.

\subsection{Rationale and justification for conducting the present study}

Despite the practical significance of psychology as a science-based school subject in Brunei, there has not been a comprehensive assessment and evaluation of the barriers to and enablers of achievement in Brunei General Certificate of Education Advanced Level psychology. Research on Brunei student population that reports findings on teaching and learning of psychology is still sparse, if not absent, in major journals. The present study was thus novel in four ways:

- First, using quantitative and qualitative data from two relevant subsamples, the study identified both the barriers to and enablers of success in psychology.

- Second, the study offers various insights and suggestions on how the barriers may be reduced and eventually eliminated. 
- Third, it is the first time the evaluation of teaching, learning, and assessment in psychology with Year 13 (GCE Advanced Level) students was done in Brunei.

- Fourth, cultural factors were examined as they impact teaching and learning in the Brunei situation.

\subsection{Theoretical framework}

The conceptual framework for the current study is underpinned by theories that allude to the relationship between teaching and assessment. Shernoff et al. (2003) found that students were more engaged in tasks or activities when they felt that: (1) they had the skills to complete the tasks; (2) instructions pertaining to the tasks given to them were adequate; and (3) had control of the learning environment. For a student to accomplish different tasks, a number of constructs need to be taken into account, such as expectancies for success in tasks (Wentzel \& Wigfield, 1998). Thus, the perception of ability was likely to affect students' decisions to further their studies (Chevalier et al., 2007). In addition, research has shown that positive attitudes towards the self and school ultimately determines the students' motivation and effort in doing school work (Haladyna, Shaughnessy \& Shaughnessy, 1983). This is because students' perceptions of themselves influence the amount of effort they are willing to give in school, their educational aspirations, and their academic achievement (Ajzen \& Fishbein, 1977; Byrne \& Shavelson, 1986). Brunei GCE A-Level students have high interest and positive attitudes toward psychology which they take as an optional school subject. For reasons explained above under the introduction, the students appear to be intrinsically motivated to learn the subject. Thus, the prevailing and ongoing student underachievement in the subject can be attributed to other factors to be identified by the present and future studies.

\section{Literature review}

\subsection{Teaching and assessment of Brunei GCE A-Level psychology}

The teaching and assessments in Brunei GCE A-Level psychology are researchbased and conducted in English. In particular, teaching and assessments are based on psychological problems published in reputable reviewed journals produced by major publishers such as Sage, Taylor and Francis, Wiley, Springer, Elsevier, and Emerald. Moreover, the Brunei GCE AS-Level and GCE A-Level psychology examinations are modeled on the UK Cambridge International Examinations and are part of this testing system. Classroom teaching, learning and assessment activities require students to actively interact with journal articles using higher-order skills such as critical thinking, understanding, analysis, synthesis, application, and evaluation. Two major problems arise out of this situation. First, both the teaching materials used (books and journal articles) and assessment instruments administered (final summative examinations) are written in standard western English (British and American) that Brunei students sometimes find difficult to comprehend for reasons briefly explained below in a separate passage. Second, the majority of the journal articles used contain quantitative research that students with little or no statistics background cannot understand. Like in previous research (Rugerri et al., 2008), it is quite possible 
that some of the Brunei students studying psychology may not have anticipated encountering statistics in this subject. This problem is also separately and briefly explained in detail below.

\subsection{English as a medium of instruction and testing}

Evidence from previous research further suggests that language barriers may affect performance in school (Teruel, Parker and Rubalcava (2003). This is more so in situations where, for example, the medium of instruction is English but this language is not native to both students and teachers. Moreover, Abedi (2004) also found that the linguistic complexity of assessment tools used in subjects decreased performance in the areas with greater language demand for students with limited English proficiency (LEP). Both of these previous studies highlight the impact of language barriers in determining educational achievement. This is especially so in countries such as Brunei where English, the medium of instruction, is spoken and used as a second or third language. Furthermore, the kind of questions teachers ask and the way in which they are asked in a given language can, to a large extent, influence the nature of students' thinking as they engage in the process of constructing knowledge (Chin, 2007). Due to language barriers, it is quite possible that some Brunei students give wrong answers in psychology examinations due either to not understanding the questions adequately or writing weak responses that lack effective exposition and clarity of expression when using statistical language.

\subsection{Statistics as a sticking problem in GCE A-Level psychology}

Mathematics (which includes topics in statistics) in Year 11 (GCE O-Level), is not a core or compulsory (but rather an optional) subject at GCE AS-Level and GCE A-Level in the Brunei education system. In addition, quantitative research is also not taught as a school subject throughout the education system up to GCE ALevel in Brunei. Thus most Brunei Year 12 (GCE AS-Level) and Year 13 (GCE ALevel) students encounter complex research, psychometric, and statistical concepts such as "randomized control designs", "reliability and validity", and "effect size" respectively without sufficient and appropriate background. This lack of suitable background in quantitative research, psychometrics, and statistics appears to be a formidable barrier to achievement in Brunei students' psychology examinations at GCE AS-Level and GCE A-Level. As a result, Brunei students seem to find statistics to be the most challenging aspect of the psychology subject in line with findings of previous studies (e.g. Barry, 2012). In addition, previous research indicates that a number of students experience statistics anxiety (Onwuegbuzie \& Wilson, 2003; Onwuegbuzie, 2004). Previous research showed that there were six facets of statistical anxiety: test and class anxiety; interpretation anxiety; anxiety about asking for help; understanding the worth of statistics; fear of statistics teachers; and negative computational selfconcept (see Cruise et al., 1985; Baloglu, 2002; Hanna et al., 2008; Bourne, 2018). Students who score high on statistics anxiety scales tend to underachieve in courses with a lot of statistics (Hanna \& Dempster, 2009; Macher et al., 2012). However, it was unclear how these six aspects of statistics anxiety affected participants in the present study since this variable was not directly measured. 
Nevertheless, educators and educational researchers have proposed many different ways for addressing statistical anxiety. Harvey (2009) suggested using a general numeracy test as a predictor of undergraduate statistics performance. Potential students, who scored low on the predictor variable, would then be counseled before taking a statistics laden module (Huws et al., 2005; Harvey, 2009). Other educational practitioners (e.g. Huang \& Mayer, 2016) have emphasized improving students' coping skills to reduce statistics anxiety. Lloyd and Robertson (2012) advocated improving the students' mathematical and statistical skills such as calculating, interpreting, and evaluating.

\subsection{Considerations on improving Brunei psychology students' achievement}

Improving teaching and learning are among the biggest concerns of teachers, educational psychologists and school counselors. One perspective that is quite important to focus on in this regard is students' perceptions, as students are arguably the more important participants in the teaching and learning business (Schunk \& Meece, 1992). In the classroom, student perceptions about the lessons may influence behaviors such as motivation, learning attitudes, as well as academic performance. For example, if a student has negative perceptions of a lesson or class, this may negatively impact her or his motivation to learn, generate negative attitudes toward teachers, and adversely affect academic performance. Another important student perception is the learner's selfperception in terms of ability. Researchers have found that students who percieved themselves to have high ability tend to have higher levels of motivation and achieve higher grades (Skinner, Wellborn \& Connell, 1990). The current study was designed to elaborate on these and other related problems using a sample of Brunei GCE A-Level psychology students.

\subsection{Brunei psychology students' help-seeking strategies}

Other than students' perceptions about classes and lessons, another factor that may influence teaching and learning was academic help-seeking. Appropriate help-seeking behavior was important for students who were struggling and may contribute to a student's success. Some researchers suggest that help-seeking behaviors are part of strategies for self-regulated learning (Paris \& Newman, 1990) often shown by students who achieve high grades (Zimmerman \& Martinez-Pons, 1986). For instance, high achieving students may be more motivated to engage in help-seeking behaviors, perhaps to clarify ambiguous information, in order to gain a fuller understanding of the subject matter, rather than passively accepting what was read or said (Ames, 1983).

\subsection{Objectives of the study}

Due to various unresearched problems and challenges facing the educational system, academic achievement in Brunei GCE AS-Level and GCE A-Level psychology examinations have not been particularly good despite the students' interest in the subject. Due further to lack of research in significant journals, not much is known about Brunei GCE A-Level psychology students' achievement problems. It is hoped the current study would narrow the literature and knowledge gaps on this matter. The goal of the current study was to: 
(a) Identify the factors perceived by Brunei trainee psychology teachers as enablers and barriers to Year 13 students' achievement in psychology; and

(b) Identify the factors perceived by Brunei Year 13 students as enablers and barriers to achievement in psychology.

\section{Method}

The research method for the present study is explained below under the design, participants, instruments, procedures, and data analysis.

\subsection{Design}

A descriptive field survey design was used to carry out the study. This design was chosen as it was easier to conduct and had fewer problems (e.g. in accessing the participants) than other survey research methods (e.g. online, postal, telephone, and longitudinal).

\subsection{Participants}

This study had two sample groups namely, Year 13 psychology students in Sixth Form government schools $(\mathrm{N}=118)$ and all psychology student teachers at SHBIE, UBD $(\mathrm{N}=9)$ during the year the study was conducted who were training to teach psychology subject to Year 12 and Year 13 students. The Sixth Form Centers are pre-university institutions in the Brunei education system serving as a foundation stage for students who want to enter university.

Of the nine (9) student teachers, seven (7) were women while two (2) were men. These were the only registered trainee psychology teachers during the academic in which the study was conducted and represented the population for this category of participants. Each of them previously studied psychology in Year 12 and Year 13 and had a bachelor's degree or higher in psychology or counseling. The student teachers were attached to schools for two days per week to practice teaching. This was done throughout the two years (four semesters) duration of their teacher education course. These school placements enabled trainee teachers to acquire practical experience in teaching, testing, assessing, and evaluating GCE AS-Level and GCE A-Level psychology students in actual and real-life school environments. The assessments were performed according to Brunei Teacher Standards (Ministry of Education, 2013). The school attachments further enabled student teachers to be familiar with plausible factors preventing Sixth Form psychology students from achieving high in examinations. This subsample knew more about the psychology subject and were thus administered a more specific and detailed research instrument.

At the time of collecting data for the current study, the total number of Year 13 psychology students in the country was not known. The Year 13 participants were selected by the simple random sampling technique from five different schools located in Brunei-Muara district (3 schools), Tutong (1), and Kuala Belait (1). Temburong, the fourth district of Brunei, did not have Year 13 psychology students. Only Year 13 psychology students were recruited for the study. All the 
Year 13 participants had completed GCE AS-Level psychology the previous school year. Data collection for the current study was conducted during the middle of the participants' GCE A-Level academic year before their final summative national examinations. The high school participants were fully aware of problems they encountered during the teaching, learning, assessment and evaluation of psychology at Year 12 (AS-Level) and Year 13 (A-Level). Of the 118 GCE A-Level participants selected, 84 (71\%) were women while 34 or $29 \%$ were men. Ethnically, the Year 13 subsample consisted of 94 (80\%) Malays, 19 (16\%) Chinese, and $5(4 \%)$ other students from different racial groups. The majority of them $(109$ or $92 \%)$ were full Brunei citizens and $9(8 \%)$ were permanent residents. In terms of religion, 98 (83\%) were Muslim, 17 (14\%) followed other faiths, and $3(3 \%)$ did not adhere to any religion. The age range for GCE A-Level students was 18-20 (Mean $=19.637 ; \mathrm{SD}=1.281)$. On the other hand, the 9 trainee teachers comprised of 7 females and 2 males aged between 21 and 24 (Mean = 22.333; $\mathrm{SD}=1.000$ ). They were all Brunei citizens (one Chinese and 8 Malays).

\subsection{Instruments}

One researcher-constructed qualitative instrument with three sections was used to collect the required data. Part A was administered to both sample groups (trainee psychology teachers and GCE psychology students) and collected demographic data such as gender, age, ethnicity, religion, citizenship, and location of the school. This information was used in describing the sample.

Part B was administered to psychology trainee teachers only $(n=9)$. It consisted of 18 items that participants rated on 5-point Likert scales $(\mathrm{SD}=1 ; \mathrm{D}=2 ; \mathrm{N}=3$; $\mathrm{A}=4 ; \mathrm{SA}=5)$ to determine whether the item statement represented a factor that was a barrier to or an enabler of achievement and success in GCE A-Level psychology examinations. The statements were gleaned from relevant literature review sources. Sample statements in this section included: ability to think critically; skills in mathematics and statistics; and research knowledge and skills. Items with mean scores $\leq 3$ were labeled as barriers or inhibitors to achievement while those with mean scores $\geq 4$ were designated as enablers or facilitators of achievement. An item with Mean $=3$ was regarded as a neutral factor (neither a barrier to, nor an enabler of) achievement and success in psychology. All the criterion cut-off mean scores were chosen by the researcher. Because of the small subsample $(n=9)$ and the number of scale items (18) being larger than the sample size, exploratory factor analysis could not be performed to determine the specific subscales underlying the 18 items. In addition, the 18 items measure different learning and study skills. Due to these two reasons, the alpha reliability could not be computed though the 18 items were scored on 5-point Likert scales. Furthermore, in the absence of factor analysis, the construct validity of the 18item scale could not also be obtained. The quality of the 18-item scale was therefore determined in two other ways. First, two experienced Year 13 psychology teachers (male and female) independently and blindly coded each of the 18 items as suitable (1) or unsuitable (0) for purposes of the present research. The resultant intercoder agreement reliability index was $83 \%$. Second, another different set of two experienced Year 13 psychology teachers (female and male) 
also separately and blindly concurred that the 18-item instrument had good content validity.

Part $\mathrm{C}$ was comprised of three unstructured self-report items designed to assess aspects of the GCE A-Level psychology subject that participants liked and disliked and those that needed to be innovated or changed. The items in this section included the following statements: (1) In the space below, briefly explain what you liked most about the GCE A-Level psychology subject that helped you to perform well; (2) In the space below, briefly explain what you disliked most about the GCE A-Level psychology subject that prevented you from performing well; and (3) In the space below, briefly explain what you think should be done to improve students' achievement in GCE A-Level psychology subject. Two trained female graduate research assistants separately, independently and blindly content analyzed the responses to these three open-ended statements. The interrater agreement percentage reliability indices on these items were $87 \%$ on Item 1; 70\% (Item 2); and 81\% (Item 3). Furthermore, two experienced GCE psychology teachers independently and blindly judged the three items as having adequate content validity for the current study. Overall, the analyses yielded more than two themes and categories of responses on each item.

\subsection{Procedures}

The students were informed about the objectives of the study as well as the ethical conditions for being involved in the research. This was done prior to recruiting the participants in the study. Only those participants who voluntarily agreed to take part were recruited. The entire research instrument was written in simple English requiring only Year 7 education and did not require to be translated into Bahasa Melayu, the majority and official language of Brunei. However, participants who needed help in completing the instruments properly were assisted. This was carefully done without influencing the participants' responses.

\subsection{Data analysis}

With regard to the analysis of quantitative data, only descriptive statistics (frequencies, percentages, mean scores, standard deviation, and confidence intervals) were used. More importance was attached to trends, patterns, and practical significance rather than statistical significance. Content analysis with constant comparison, categories, themes, and excerpts were used in analyzing qualitative data following the procedures recommended by Lincoln and Guba (1985) and Patton (1990).

\section{Results}

The findings are presented below according to the two broad objectives of the study outlined above. 


\subsection{Factors perceived by trainee psychology teachers as enablers and barriers to achievement in psychology}

Psychology student teachers viewed 11 of the 18 statements listed in Table 1 as enablers for achievement in GCE A-Level psychology (Mean scores $\geq 4$ ). The criterion value $\geq 4$ was chosen arbitrarily by the researcher. These factors included: early identification of vulnerable learners; effective teaching; appropriate study methods; possessing higher-order learning skills; ability to think critically; having positive self-concept and self-esteem; availability of suitable learning materials or resources; motivation; receiving help; and facility in English language. Factors with high mean scores $\geq 4$ had relatively lower standard errors compared to those with low mean scores. For each of the above attributes, any obtained mean score $\geq 4.00$ was significantly different at $p<.05$ from any obtained lower mean score $\leq 3.00$ on a 5-point Likert rating scale (1SD, 2D, 3N, 4A, 5SA). For example (in Table 1), the obtained mean score on "Identification of vulnerable students at risk of failing" was $4.333($ SEm $=0.166)$. The $95 \%$ confidence interval (CI) for this obtained mean score was $4.333 \pm[(1.96)$ $(0.166)]$ or 4.008-4.658, where 1.96 (nearly 2.00) is a Z-score. On the other hand, the $95 \%$ CI for an obtained mean 3.000 on "Identification of vulnerable students at risk of failing" would be $3.000 \pm 0.325=2.675-3.325$. In this instance, the lower limit of the mean score 4.333 did not overlap with the upper limit of the mean score 3.000. Based on this reasoning, it can be said that a mean score of 4.333 on the "Identification of vulnerable students at risk of failing" variable was significantly different from any mean score $\leq 3.000$ at $\mathrm{p}=0.05$ level on a 5-point Likert rating scale (1SD, 2D, 3N, 4A, 5SA). Similarly, all the other 10 characteristics listed above had high mean scores $(\geq 4.00)$ that were significantly different from lower mean scores $(\leq 3.000)$ on their respective 5-point Likert scales. This was partly due to the fact that all the high mean scores $(\geq 4.00)$ had relatively low standard errors. The standard error of the mean (SEm) was used in two ways in the present study. First, it was considered to be the reliability of each mean score. The smaller the SEm value, the more reliable the mean score was. Second (as shown above), the SEm was used in constructing the 95\% CI for each mean score in which the true mean value lay.

The main barriers to achievement were (Mean scores $\leq 2.888$ ): lack of clarity and specificity in some questions; low-level skills in mathematics and statistics; inadequate research knowledge and skills; and absence of educational, psychological, and counseling interventions. These factors had relatively higher standard errors compared to those with high mean scores listed above. Several factors (with mean scores ranging from 3.333 to 3.888) did not seem to have had substantial positive or negative effects on achievement in GCE A-Level psychology. The examples of these factors are: learning styles; personality characteristics; and interest in psychology-related careers. 
Table 1: Psychology trainee teachers' views on factors facilitating and hindering GCE A-Level students' achievement in psychology $(\mathrm{N}=9)$

\begin{tabular}{|c|c|c|c|c|}
\hline Item† & Mean & SEmean $^{\mathrm{a}}$ & $\begin{array}{l}\text { Standard } \\
\text { Deviation }\end{array}$ & $\begin{array}{l}\text { Opinion } \\
\text { (direction)* }\end{array}$ \\
\hline $\begin{array}{l}\text { 1. Identification of vulnerable students at risk of } \\
\text { failing }\end{array}$ & 4.333 & 0.166 & 0.500 & + \\
\hline 2. Teaching effectiveness & 4.444 & 0.175 & 0.527 & + \\
\hline 3. Specificity and clarity of test items & 2.888 & 0.200 & 0.600 & - \\
\hline 4. Learning styles & 3.888 & 0.351 & 1.054 & $\mathrm{~N}$ \\
\hline 5. Study strategies & 4.666 & 0.166 & 0.500 & + \\
\hline 6. Personality characteristics & 3.333 & 0.288 & 0.866 & $\mathrm{~N}$ \\
\hline 7. Higher-order skills & 4.444 & 0.242 & 0.726 & + \\
\hline 8. Critical thinking ability & 4.111 & 0.200 & 0.600 & + \\
\hline 9. Research knowledge and skills & 2.777 & 0.222 & 0.666 & - \\
\hline 10. Mathematical / statistical skills & 2.888 & 0.423 & 1.269 & - \\
\hline 11. Self-concept & 4.000 & 0.166 & 0.500 & + \\
\hline 12. Self-esteem & 4.000 & 0.166 & 0.500 & + \\
\hline 13. Learning materials / resources & 4.666 & 0.166 & 0.500 & + \\
\hline 14. Motivation & 4.333 & 0.166 & 0.500 & + \\
\hline 15. Interest in psychology-related careers & 3.444 & 0.412 & 1.236 & $\mathrm{~N}$ \\
\hline 16. Help-seeking behaviors & 4.333 & 0.333 & 1.000 & + \\
\hline $\begin{array}{l}\text { 17. Educational, psychological, and counseling } \\
\text { interventions }\end{array}$ & 2.555 & 0.242 & 0.726 & - \\
\hline $\begin{array}{l}\text { 18. Understanding and effective use of English } \\
\text { language }\end{array}$ & 4.444 & 0.175 & 0.527 & + \\
\hline
\end{tabular}

\subsection{Factors perceived by GCE A-Level psychology students as enablers and barriers to achievement in psychology}

Table 2 shows the themes, categories and non-additive frequency counts that emerged from content analyses of qualitative data (with constant comparison) on the following question posed to GCE A-Level psychology students: what do you like most about psychology teaching and examinations that helps you to perform well? Positive feelings about psychology, practice questions, and shortanswer items were, in different ways, regarded by GCE psychology students to be enablers of achievement. Regarding positive feelings, many students wrote comments such as: "psychology was interesting to study"; "I feel I will perform well in this subject"; and "I have enough motivation to study this subject". These excerpts were similar (in some ways) to the self-concept, self-esteem, and motivation issues and qualities endorsed by trainee teachers above (see Table 1). Short answer items did not require much mastery of English to write and perform well (Table 1) compared to long essays. Critical thinking, in particular, was identified as a facilitator of achievement by both trainee psychology teachers (Table 1) and GCE psychology students (Table 2). Practice questions, for example, provided help in answering future examination questions correctly according to GCE psychology students (see Table 2). Similarly, psychology student teachers also mentioned help-seeking as an enabler of success (Table 1). Short-answer questions were preferred by GCE A-Level psychology students because they do 
not involve complicated English to comprehend and write as reported in Table 2. This finding could be directly compared or contrasted to the responses of trainee psychology teachers in Table 1 who viewed poor specificity and clarity in test items as barriers to achievement but considered good understanding and use of English language as enablers of success.

Table 2: Explain what you like most about psychology teaching and examinations that helps you to perform well $(\mathrm{N}=118)$

\begin{tabular}{|c|c|c|c|c|}
\hline Theme & Description & Categories of responses & Frequency & Total \\
\hline 1 & $\begin{array}{l}\text { Feelings about } \\
\text { psychology }\end{array}$ & $\begin{array}{c}\text { Requires critical thinking } \\
\text { Interesting } \\
\text { Curiousity arousing } \\
\end{array}$ & $\begin{array}{c}9 \\
10 \\
2 \\
\end{array}$ & 21 \\
\hline 2 & $\begin{array}{l}\text { Practice questions and } \\
\text { tests }\end{array}$ & $\begin{array}{c}\text { Help in answering future } \\
\text { exam questions }\end{array}$ & 15 & 15 \\
\hline 3 & Exam paper structure & $\begin{array}{l}\text { Short-answer questions } \\
\text { (direct/easy to } \\
\text { understand) were fair } \\
\text { Evaluation questions } \\
\text { were interesting but } \\
\text { challenging } \\
\text { Long essays - questions } \\
\text { on strengths and } \\
\text { weaknesses of articles } \\
\text { (repeated from past } \\
\text { years) were difficult }\end{array}$ & 45 & 65 \\
\hline
\end{tabular}

Table 3 shows the themes, categories and non-additive frequency counts generated from content analyses of qualitative data (with constant comparison) on the following question posed to GCE A-Level psychology students: what do you dislike most about psychology teaching and examinations that prevents you from doing well? The various categories of responses received on this question were grouped into three themes presented in Table 3. Both the themes and categories were barriers to achievement in psychology. The students' comments on problems they faced were captured and illustrated in the following few short example quotations: "the questions required recall of too much information from journal articles"; "I am not good at explaining evaluation questions"; "design questions are difficult to understand"; and "shortage of time to answer all questions". A contrast of information presented in Table 1 and Table 3 shows that trainee psychology teachers and GCE psychology students had largely different views regarding the major barriers to achievement in psychology. However, lack of specificity and clarity in test items in Table 1 (for trainee psychology teachers) was analogous and similar to the categories for the theme "difficulty in answering questions and getting full marks" in Table 3 (for GCE psychology students). 
Table 3: Explain what you dislike most about psychology teaching and examinations that prevents you from doing well $(\mathrm{n}=118)$



To improve achievement in GCE A-Level psychology examinations, psychology student participants suggested making a number of changes to teaching methods, learning strategies, assessment instruments as well as using and managing time. Sample responses received from the participants included statements such as: "we need more time to do the examination"; "had problems understanding some topics because of the teaching method used"; and "teach students to answer questions correctly". The list of themes and categories presented in Table 4 is not exhaustive but rather illustrative of the most important points they mentioned in their short written narratives. Based on the obtained findings, both psychology teachers and psychology students need to be more engaged with each other during classroom interactions and activities (Theme 1). In addition, familiarizing students with the exam format and questions was also considered to be an important strategy (Theme 2). Furthermore, good time management and proper use of available time were also implicated in improving academic achievement (Theme 3). 
Table 4: Explain what you think should be done to teaching and examinations to improve students' performance in psychology $(N=118)$

\begin{tabular}{|c|c|c|c|c|}
\hline Theme & Description & Categories of responses & Frequency & Total \\
\hline 1 & $\begin{array}{l}\text { Improvement in } \\
\text { teacher/class/student } \\
\text { activities in classroom }\end{array}$ & $\begin{array}{l}\text { Discussions - make } \\
\text { student explain a study; } \\
\text { ensure they understand } \\
\text { it; avoid misconceptions. } \\
\text { Do activities outside of } \\
\text { class; do practicals } \\
\text { Make learning fun; use } \\
\text { games/groupwork } \\
\text { Give simple summarised } \\
\text { notes } \\
\text { More use of videos and } \\
\text { documentaries } \\
\text { Recapping } \\
\text { Use simple English }\end{array}$ & $\begin{array}{c}9 \\
8 \\
10 \\
2 \\
2 \\
6\end{array}$ & 60 \\
\hline 2 & Exam strategies & $\begin{array}{l}\text { More revision; more } \\
\text { practice tests }\end{array}$ & 52 & 52 \\
\hline 3 & $\begin{array}{l}\text { Improvement with } \\
\text { time }\end{array}$ & $\begin{array}{l}\text { Teach time management } \\
\text { skills } \\
\text { Give extra classes; } \\
\text { increase class periods; } \\
\text { more time to study for } \\
\text { examinations }\end{array}$ & 5 & 11 \\
\hline
\end{tabular}

\section{Discussion}

\subsection{Barriers to academic achievement in psychology according to trainee psychology teachers}

Brunei psycholozgy students' performance in GCE A-Level psychology is not uniform across the subject topics. Trainee psychology teacher participants in the present study were of the opinion that the following factors contributed to underachievement: lack of clarity and specificity in some questions; low-level skills in mathematics and statistics; inadequate research knowledge and skills; and absence of educational, psychological, and counseling interventions

Brunei GCE A-Level examination questions are written in standard English and edited by native speakers of English who are psychology subject specialists. The claim that lack of clarity and specificity in some questions hindered achievement implied that both trainee psychology teachers and high school psychology students may have limitations in English facility. Previous research indicated that language barriers may affect performance in school (Teruel et al., 2003). Past research also showed that the linguistic complexity of assessment 
tools used in subjects decreased performance in the areas with greater language demand for students with limited English proficiency, LEP (Abedi, 2004).

The finding that low-level skills in mathematics and statistics partly hampered achievement in Brunei GCE A-Level psychology was supported by a number of relevant previous studies (Cruise et al., 1985; Baloglu, 2002; Hanna et al., 2008; Rugerri et al., 2008; Hanna \& Dempster, 2009; Barry, 2012; Macher et al., 2012; Bourne, 2018). According to these studies, students who score high on various statistics anxiety subscales often tend to underachieve in courses with a lot of statistics.

Barry's (2012) study revealed that students who got low grades only in research methods needed the same help as those who got low grades in all other topics particularly statistics. However, one study found that the subjects studied at Alevel (e.g. psychology), and the grades obtained there, did not necessarily predict performance in the same discipline at university level (Huws et al., 2005). These two previous studies support the notion, in the present study, that inadequate research knowledge and skills contributed to underachievement in Brunei GCE A-Level psychology students.

\subsection{Barriers to academic achievement in psychology according to GCE A-Level psychology students}

There are many ways in which performance and achievement in GCE A-Level psychology could be improved. Brunei GCE A-Level psychology student participants in the current study cited the need to practice answering relevant psychology questions to improve examination strategies. In particular, student participants also mentioned the importance of seeking help on how to answer examination questions effectively to improve achievement. The development and acquisition of critical thinking and time management skills were also considered to be essential in raising the level and standard of performance and achievement in Brunei GCE advanced psychology. These findings were variously supported by the literature in the current study. For example, some researchers suggested that help-seeking behaviors were part of strategies for self-regulated learning (Paris \& Newman, 1990) often shown by students who achieve high grades (Zimmerman \& Martinez-Pons, 1986). However, Lloyd and Robertson (2012) advocated improving the students' mathematical and statistical skills such as calculating, interpreting, and evaluating. On the other hand, Huang \& Mayer (2016) emphasized improving students' coping skills to reduce statistics anxiety.

\subsection{Enablers of academic achievement in psychology according to all participants}

Besides critical thinking skills (one of several higher-order skills needed), having superior English skills, and receiving appropriate help on answering examination questions correctly, three other important enablers of achievement identified by both trainee teachers and GCE A-Level psychology students were matters pertaining to self-concept, self-esteem and motivational levels. Previous 
research has shown that students who consider or regard themselves to have ability in the subject tend to have higher levels of motivation and achieve higher grades (Skinner et al., 1990). Furthermore, research indicated that positive attitudes towards the self and school determines (to some extent) the students' motivation and effort in doing school work (Haladyna et al., 1983). Students' self-perceptions influence the amount of effort they commit to school, their educational objectives, and academic achievement (Ajzen \& Fishbein, 1977; Byrne \& Shavelson, 1986).

\section{Conclusion}

There is a steady and growing demand for psychology in Year 12 and Year 13 of the Brunei education system despite low performance by students in the subject. The present study identified some of the barriers to and enablers of achievement using samples of trainee psychology teachers and GCE A-Level psychology students. To name a few, the barriers to achievement included weaknesses in written English, problems with statistics, and lack of research skills to address design-based questions. Possession of strong English skills, higher-order skills such as critical thinking, and receiving appropriate help on responding to questions effectively were among the many enablers of achievement revealed by the current study. Two key recommendations are made based on the findings. First, the barriers to achievement need to be addressed especially issues concerning statistics and research design. Second, mixed methods research incorporating interview probes needs to be undertaken to better understand the problems and possible solutions.

\section{Limitations}

This study had one major limitation. It needed an interview component to probe findings from the quantitative survey and the open-ended qualitative section. Future research should address this research gap.

\section{References}

Abedi, J. (2004). The no child left behind act and English language learners: Assessment and accountability issues. Educational Researcher, 33(1), 4-14. https:// doi.org/10.3102/0013189X033001004

Ajzen, I., \& Fishbein, M. (1977). Attitude-behavior relations: A theoretical analysis and review of empirical research. Psychological Bulletin, 84(5), 888-918.

Ames, R. (1983). Help-Seeking and Achievement Orientation: Perspectives from attribution Theory. In B. M. DePaulo, A. Nadler \& J. D. Fisher (Eds). New Directions in Helping. (Vol. 2, pp. 165-186). New York: Academic Press.

Baloglu, M. (2002). Psychometric properties of the statistics anxiety rating scale. Psychological Reports, 90(1), 315-325. https://doi.org/10.2466/PR0.90.1.315-325

Barry, J. A. (2012). Do students who get low grades only in research methods need the same help as students who get low grades in all topics in psychology? Psychology Teaching Review, 18(2), 116-125.

Bourne, V. J. (2018). Exploring statistical anxiety: Contrasting mathematical, academic performance and trait psychological predictors. Psychology Teaching Review, 24(1), 35-43. 
Byrne, B. M., \& Shavelson, R. J. (1986). On the structure of adolescent self-concept. Journal of Educational Psychology, 78(6), 474-481.

Chevalier, A., Gibbons, S., Thorpe, A., Snell, M., \& S. Hoskins (2007). Students' academic self-perception. IZA DP3031. Retrieved from: http://ftp.iza.org/dp3031.pdf (Accessed on 29 April 2018).

Chin, C. (2007). Teacher questioning in science classrooms: Approaches that stimulate productive thinking. Journal of Research in Science Teaching, 44(6), 815-843. https://doi.org/10.1002/tea.20171

Cruise, R., Cash, R., \& Bolton, D. (1985). Development and validation of an instrument to measure statistical anxiety. Paper presented at the annual meeting of the Statistical Education Section, Chicago.

Haladyna, T., Shaughnessy, J., \& Shaughnessy, J. M. (1983). A causal analysis of attitudes toward mathematics. Journal of Research in Mathematics Education, 14, 19-29.

Hanna, D., \& Dempster, M. (2009). The effect of statistics anxiety on students' predicted and actual test scores. The Irish Journal of Psychology, 30(3-4), 201-209. https://doi.org/10.1080/03033910.2009.10446310

Hanna, D., Shevlin, M., \& Dempster, M. (2008). The structure of the statistics anxiety Rating scale: A confirmatory factor analysis using UK psychology students. $\begin{array}{llll}\text { Personality and Individual Differences, 45(1), 68-74. } & \end{array}$ https://doi.org/10.1016/j.paid.2008.02.021

Harvey, A. J. (2009). The merits of a general numeracy test as a predictor of undergraduate statistics performance. Psychology Learning and Teaching, 8(2), 1622. https://doi.org/10.2304/plat.2009.8.2.16

Huang, X., \& Mayer, R. E. (2016). Benefits of adding anxiety-reducing features to a computer-based multimedia lesson on statistics. Computers in Human Behavior, 63, 293-303.

Huws, N., Reddy, P., \& Talcott, J. (2005). Predicting university success in psychology: Are subject-specific skills important? Psychology Learning and Teaching, 5(2), 133140. https://doi.org/10.2304/plat.2005.5.2.133

Lincoln, Y. S., \& Guba, E. G. (1985). Naturalistic inquiry. Newbury Park, CA: Sag Publications.

Lloyd, S. A, \& Robertson, C. L. (2012). Screencast tutorials enhance student learning of $\begin{array}{lllll}\text { statistics. } & \text { Teaching }\end{array}$ https://doi.org/10.1177/0098628311430640

Macher, D., Paechter, M., Papousek, I., \& Ruggeri, K. (2012). Statistics anxiety, trait anxiety, learning behavior, and academic performance. European Journal of Psychology of Education, 27(4), 483-498.

Ministry of Education. (2013). Brunei Teacher Standards. Bandar Seri Begawan: Government Printer.

Onwuegbuzie, A. J. (2004). Academic procrastination and statistics anxiety. Assessment and Evaluation in Higher Education, 29(1), 3-19. https://doi.org/10.1080/0260293042000160384

Onwuegbuzie, A. J., \& Wilson, V. A. (2003). Statistics anxiety: nature, etiology, antecedents, effects and treatments - a comprehensive review of the literature. Teaching in Higher Education, 8(2), 195-209. https:// doi.org/10.1080/1356251032000052447

Paris, S. G., \& Newman, R. S., (1990). Developmental aspects of self-regulated learning. Educational Psychologist, 25, 87-102.

Patton, M. Q. (1990). Qualitative evaluation and research methods. Newbury Park, CA: Sage Publications.

Ruggeri, K., Dempster, M., Hanna, D., \& Cleary, C. (2008). Experiences and expectations: The real reason nobody likes stats. Psychology Teaching Review, 14(2), 75-83. 
Shernoff, D. J., Mihaly Csikszentmihalyi, M., Barbara Shneider, B., \& Elisa S. Shernoff, E. S. (2003). Student engagement in high school classrooms from the perspective of flow theory. School Psychology Quarterly, 18(2), 158-176. https:// doi.org/10.1521/scpq.18.2.158.21860

Schunk, D. H., \& Meece, J. L. (Eds.). (1992). Student perceptions in the classroom. Hillsdale, NJ: Lawrence Erlbaum Associates, Inc.

Skinner, E. A., Wellborn, J. G., \& Connell, J. P. (1990). What is Takes to Do Well in School and Whether I've Got It: A Process Model of Perceived Control and Children's engagement and Achievement in School. Journal of Educational Psychology, 82, 22-32.

Teruel, G., Parker, S. W., \& Rubalcava, L. (2003). Language barriers and schooling inequality of the indigenous in Mexico. Economic Development and Cultural Change, 54(1), 71-94.

Wentzel, K. R., \& Wigfield, A. (1998). Academic and social motivational influences on students' academic performance. Educational Psychology Review, 10(2), 155-175. http://dx.doi.org/10.1023/A:1022137619834

Zimmerman, B. J., \& Martinez-Pons, M. (1986). Development of a Structured Interview for Assessing Student Use of Self-Regulated Learning Strategies. American Educational Research Journal, 23, 614-628. 